\title{
Research on the Influence of the Change of Consumption Concept on the Development of Digital Products in the Post Epidemic Era
}

\author{
Deng Jieru*, Xiao Canjun, Zhou Mengzhou and Zhou Xiying \\ School of Chengdu Technological university, Chengdu, Sichuan, 611730, China
}

\begin{abstract}
The outbreak of the COVID-19 epidemic has caused a huge impact on the global economy. Great changes have taken place in people's consumption patterns. In order to explore the changes of people's consumption concept in the post epidemic era, and the impact of these changes on digital products, this paper analyzes the changes of consumption concept from different life scenes such as life, work, learning, entertainment. Then, the article summarizes the development trend of digital products in the post epidemic era. Finally, the key points of future digital product design are put forward.
\end{abstract}

\section{Introduction}

The outbreak of the Covid-19 epidemic in 2020 has triggered changes in the world pattern and caused a huge impact on the global economy. People's life form and consumption form have also changed a lot. Although the change broke out in a short time, its influence will continue.

The period after the epidemic is called "post epidemic era". It refers to a new development period in which social, economic, cultural and other aspects have undergone profound changes under the influence of such a large-scale epidemic. In this new period, with the change of people's psychology and physiology, it will lead to the change of consumption concept. Thus brought the innovation of consumption form, and also had an impact on the product form of this era.

\section{Change of consumption concept in post epidemic Era}

According to the "45th China Internet Development Statistics Report" by CNNIC [1], as of March 2020, the number of Internet users in China reached 904 million, an increase of 75.08 million compared with the end of 2018 , and the Internet penetration rate reached $64.5 \%$, an increase of 4.9 percentage points compared with the end of 2018. The proportion of mobile Internet users in China has further increased, accounting for an increase of 897 million, an increase of 79.92 million compared with the end of 2018 , accounting for $99.3 \%$, and an increase of 0.7 percentage points compared with the end of 2018 . The huge number of users has created a huge digital product market. In the post epidemic era, the change of consumption concept has accelerated the development of traditional consumption to digital consumption.

Table 1. Comparison of user scale in various digital consumption scenarios in 2018-2020

\begin{tabular}{|c|c|c|c|c|c|}
\hline \multirow[t]{2}{*}{$\begin{array}{l}\text { Consumption } \\
\text { scenario }\end{array}$} & \multicolumn{2}{|c|}{$\begin{array}{l}\text { User scale (million) (network / mobile } \\
\text { network) }\end{array}$} & \multicolumn{2}{|c|}{ Usage (\%) (network / mobile network) } & \multirow{2}{*}{$\begin{array}{c}\text { Growth rate }(\%) \\
\text { (network / mobile } \\
\text { network) }\end{array}$} \\
\hline & 2018.12 & 2020.03 & 2018.12 & 2020.03 & \\
\hline Shopping ${ }^{1}$ & $610.11 / 59.191$ & $710.27 / 707.49$ & $73.6 / 72.5$ & $78.6 / 78.9$ & $16.4 / 19.5$ \\
\hline Catering $^{2}$ & $406.01 / 397.08$ & $397.80 / 396.53$ & $49.0 / 48.6$ & $44.0 / 44.2$ & $-2.0 /-0.1$ \\
\hline $\begin{array}{l}\text { Travel }^{3} \\
\text { Traffic }^{4}\end{array}$ & $\begin{array}{l}41.001 \\
389.47\end{array}$ & $\begin{array}{l}372.96 \\
362.30\end{array}$ & $\begin{array}{l}49.5 \\
47.0\end{array}$ & $\begin{array}{l}41.3 \\
40.1\end{array}$ & $\begin{array}{l}-9.0 \\
-7.0\end{array}$ \\
\hline $\operatorname{Im}^{5}$ & $791.72 / 780.29$ & $896.13 / 890.12$ & $95.6 / 95.5$ & $99.2 / 99.2$ & $13.2 / 14.1$ \\
\hline Education $^{6}$ & $201.23 / 194.16$ & $422.96 / 420.23$ & $24.3 / 23.8$ & $46.8 / 46.9$ & $110.2 / 116.4$ \\
\hline Video $^{7}$ & 724.86 & 850.44 & 87.5 & 94.1 & 17.3 \\
\hline Game $^{8}$ & $483.82 / 458.79$ & $531.82 / 528.93$ & $58.4 / 56.2$ & $58.9 / 59.0$ & $9.9 / 15.3$ \\
\hline Webcast $^{9}$ & 396.76 & 559.82 & 47.9 & 62.0 & 41.1 \\
\hline News ${ }^{10}$ & $674.73 / 652.86$ & $730.72 / 726.42$ & $81.4 / 79.9$ & $80.9 / 81.0$ & $8.3 / 11.3$ \\
\hline Music ${ }^{11}$ & $575.60 / 552.96$ & $635.13 / 632.74$ & $69.5 / 67.7$ & $70.3 / 70.5$ & $10.3 / 14.4$ \\
\hline Literature ${ }^{12}$ & $432.01 / 410.17$ & $455.38 / 452.55$ & $52.1 / 50.2$ & $50.4 / 50.5$ & $5.4 / 10.3$ \\
\hline
\end{tabular}




\subsection{Change of consumption concept in life scene}

In 2019, the network payment coverage area is becoming more and more extensive, and it accelerates the penetration into the vertical application scenarios, which promotes the integrated development of the digital economy and the real economy. We mainly choose shopping ${ }^{1}$, catering ${ }^{2}$, travel ${ }^{3}$, traffic ${ }^{4}$ and other life scenarios for analysis and research. Through the research, it is found that the scale of online shopping is expanding. With the development of logistics industry, online shopping has become very mature and widely accepted. In the aspect of catering, the data research mainly focuses on the take out scenario. The number of online take out users in China is 398 million, accounting for $44.0 \%$ of the total Internet users; the number of online take out users in mobile phones is 397 million, accounting for $44.2 \%$ of the mobile Internet users. In the comparative data, although the total number of takeout network users has declined, the number of mobile phone network users is basically the same. During the epidemic, due to regulatory measures, people reduced the use of takeout, and paid more attention to food health and hygiene issues. Travel and traffic are greatly affected by the epidemic, and the data has declined, but the scale of users is still around 350 million, accounting for about $40 \%$. Although the scale has decreased, during the epidemic, online tourism has become a new mode, such as virtual museum, online scenic spot roaming, which also reflects the change of people's consumption concept.

\subsection{Change of consumption concept in work and learning scenes}

In the working and learning scenes, the data of instant messaging $^{5}$ and online education ${ }^{6}$ are mainly selected for analysis. In the context of the epidemic, instant messaging, telecommuting, online education and other industries ushered in good development. In the aspect of individual users, instant messaging has become the basic platform of users' digital life; in the aspect of enterprise users, instant messaging applications have become the right assistant of enterprise information transformation. The function of enterprise instant messaging remote office effectively reduces the interpersonal contact in the office environment, which provides a strong support for preventing the spread of the epidemic and promoting the resumption of production. Under the influence of the epidemic situation, online education industry is the outbreak of user growth. Due to the large number of students and the inability to return to school for centralized learning in a short period of time, online education has become an export. This change in the number of users may be short-term and will gradually become stable with the school opening, but the development of distance education has also been pushed to a new period. With the adaptation of people to online work and learning scenes, the consumption habits of such products will gradually form in the future, and promote the healthy development of the industry.

\subsection{Changes in consumption concept of entertainment scenes}

For the changes in the entertainment scene, it mainly compares the data of video ${ }^{7}$, game ${ }^{8}$, webcast ${ }^{9}$, news ${ }^{10}$, music $^{11}$, literature ${ }^{12}$. In the entertainment scene, the number of users of digital products has increased by more than $10 \%$. Especially in recent years, the emergence of webcast-sales as a new form of consumer entertainment, with a growth rate of $40 \%$ and more than 550 million participants. The scale of online video users is the largest in entertainment scenes, reaching 850 million, accounting for $94.1 \%$. The second is the users of news and music, with the number of users exceeding 700 million and 600 million respectively. The third is the users of games and webcast, with the user scale exceeding 500 million. The last is the online literature users, with the scale exceeding 400 million. It can be seen that affected by the epidemic, people in the home environment, the demand for entertainment scenes is very high. Especially for the products in the form of video and audio, dynamic interaction, their users have a huge scale and their use time has been greatly improved.

\section{Development trend of digital products in post epidemic Era}

Guided by the new development concept of innovation, coordination, green, opening and sharing, China's digital economy has developed rapidly, with a scale of 31.3 trillion yuan, ranking the top in the world, accounting for $34.8 \%$ of $\mathrm{GDP}^{[1]}$. According to the user's consumption data in digital products, we can know the changing trend of user's consumption pattern. From this, we can infer the consumption characteristics of users in the post epidemic era, so as to guide the development trend of digital products. In the future, users' consumption concept will develop in three directions, namely, health, unmanned and cloud based ${ }^{[2]}$. Therefore, the development of digital products must also conform to these directions.

First of all, the pursuit of health products is essentially the pursuit of health value. This pursuit is reflected in the product, which is a process of all-round improvement of health and quality by using the product. From healthy buildings to healthy appliances, from home products to medical products, in order to improve the quality of healthy life, digital products need to create more use scenarios that are conducive to people's health. In the specific scene, let people feel the change of life quality. Paying attention to health will become a goal pursued by the whole society.

The second is to shape the scene of unmanned consumption. Under the epidemic situation, the concept of "non-contact consumption" has become popular quietly, and consumption modes such as unmanned retail, unmanned restaurant and UAV delivery have expanded new market space. Unmanned smart restaurant, contactless delivery service, etc., can reduce consumers' social 
fear, and help to maintain high efficiency and health. In terms of product form, in addition to the creation of unmanned service mode, relevant facilities and equipment in the unmanned consumption scenario also have great development potential.

The last is to create a cloud based consumption form of products and services. Through the above analysis of consumption data, it can be seen that users are increasingly dependent on remote mode in life, entertainment, work and learning scenarios. As shown in
Figure 1, by December 2019, the top four product categories of mobile application scale are games, daily tools, e-commerce and life services, accounting for more than 50\%. Among them, the number of game applications reached more than 900,000, accounting for $24.7 \%$; the number of other three categories was 514,000 , 388,000 and 317,000 , accounting for $14.0 \%, 10.6 \%$ and $8.6 \%$ respectively. Other social and educational applications accounted for $42.1 \%$. Building a cloud lifestyle is the focus of digital life in the future.

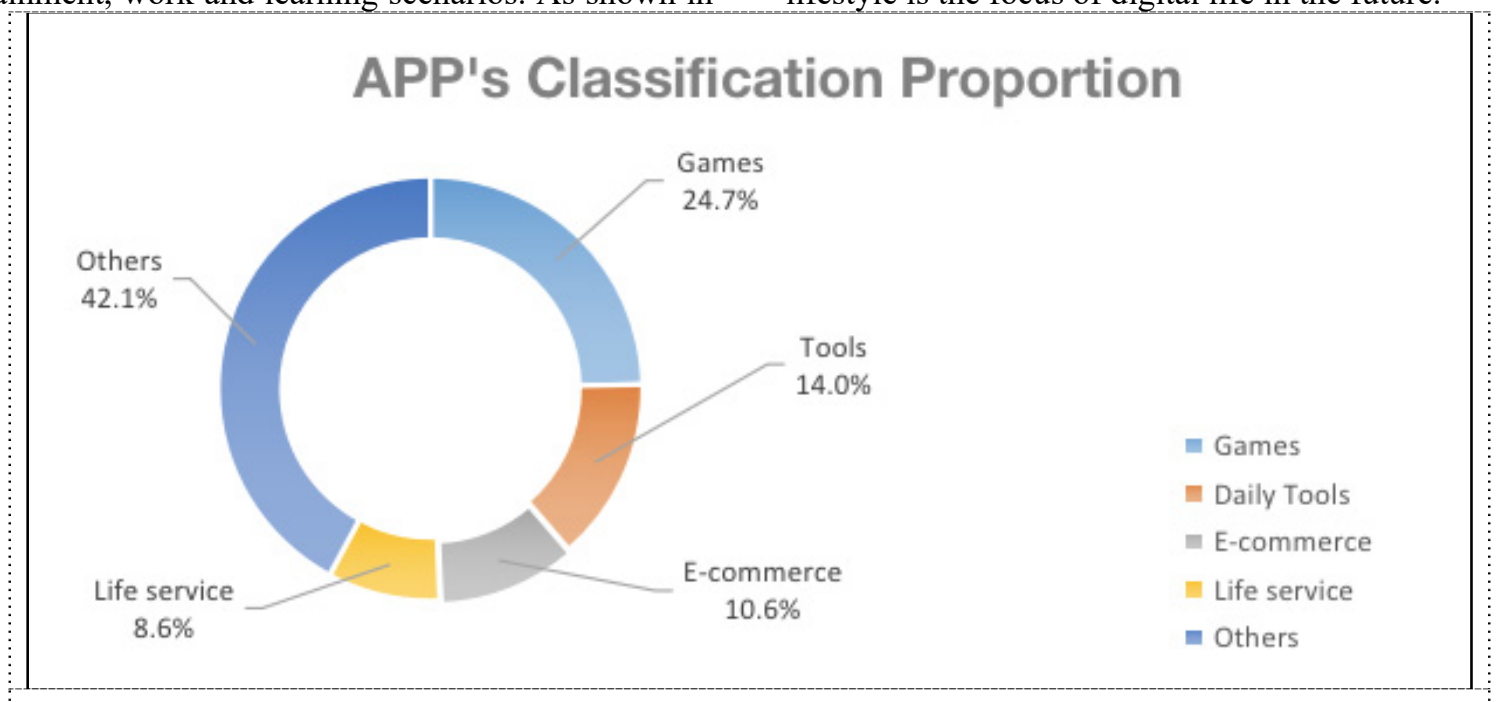

Figure 1. Classification proportion of different mobile applications ${ }^{[1]}$

\section{Key points of digital product design in post epidemic Era}

In the post epidemic era, with the trend of pursuing health, realizing unmanned and cloud based, the design of digital products will undergo some new changes. This paper mainly summarizes the new technology, new scene, new experience and new value of the product.

\subsection{New technology of digital products}

The development of technology has always been the driving force and guarantee of product innovation. Digital products need to strengthen the use of new technologies for self innovation. At the same time, the upgrading of product form will also promote the industrialization of new technology. In the post epidemic era, the rapid development of artificial intelligence, big data, cloud computing, Internet of things, blockchain and other technologies will enter a period of industrial development. Grasping the key points of technology landing in this period is an important opportunity for digital products to create new markets, such as all kinds of artificial intelligence products, data analysis products based on big data and cloud computing, smart home appliances products integrated into the Internet of things, online service products based on blockchain technology.

\subsection{New scene of digital products}

The change of consumption concept leads to the change of consumption scene. Since entering the digital era, people have become accustomed to digital consumption. Network users account for $64.5 \%$ of the total population. With the popularization of Internet infrastructure and the improvement of the quality of the national population, more users will join the digital consumption team in the future. Building a new digital consumption scenario, creating a more convenient consumption mode and meeting more users' needs can add weight to the development of the digital economy in the future. For example, the rapid rise of webcast-sales in recent years, through shaping new consumption scenarios, expanding digital sales channels, the effect is very obvious.

\subsection{New experience of digital products}

The promotion of user experience is the eternal pursuit and value of products. Digital products have the characteristics of data and visualization. We can use data technology to track and improve the user experience in the whole process. The user's use process is no longer a black box. The designer can continuously improve the user experience by tracking and analyzing the user's use data. At the same time, it can mine new user needs in user data analysis and create new consumer experience for users. In the post epidemic era, considering the changes of users' consumption psychology, such as social fear, the way of experiencing consumption will be 
more closely combined with digitalization. For example, the new experience brought by the "contact-less" consumption mode, such as unmanned restaurant and contact-less delivery, fits people's psychological needs.

\subsection{New value of digital products}

The ultimate goal of design is the pursuit of value realization. The future design of digital products should pay more attention to the return of rational value. From material shortage to material overflow, this is the only way for the development of consumer society. In the era of abundant materials, the supply side of goods has changed a lot. The demand-oriented business model requires enterprises to continuously tap the new needs of users and provide more abundant commodity forms. However, in the post epidemic era, economic development has been severely damaged, which makes people's concept of consumption more return to nature and rationality. Therefore, the design goal of digital products is not only to innovate in form, but also to tap the rational value of products. In essence, it can improve the quality of life for users.

\section{Acknowledgments}

This work was supported by Industrial Design Industry Research Center, key research base of Humanities and Social Sciences, Sichuan Provincial Department of Education. Research on the training mechanism of industrial design talents in Application-oriented Universities (GY-15YB-06). And Chengdu Technological university Research project. Innovative design of infusion assistant robot based on user experience(2018ZR013).

\section{References}

1. China Internet Network Information Center(CNNIC). (2020) 45th China Internet Development Statistics Report. http://www.cnnic.net.cn.

2. Guotai Junan consumption team.(2020) Epidemic situation reshapes consumption habits. https://www.gtja.com/content/research/industry/xf_2 00303.html.

3. Xiao Xiyin. (2020) Research on the new pattern of industrial design in the era of big data. Modern industrial economy and informatization. 202002: 4243..

4. Peng Jinxiang. (2019) Analysis of Internet users' behavior in the context of big data. Modern Industrial Economy and Informationization. 201907:62-63.

5. Hou Liye. (2019) Innovative thinking of industrial design in the era of Internet of things. Research on Industrial Innovation. 201911:40+68.

6. Banfield, R., Lombardo, C.T., Wax, T. (2015) Design Sprint: A Practical Guidebook for Building Great Digital Products. O'Reilly Media Inc. Massachusetts.

7. Sanderson, C.,Kouzoupi, N.,Hall, C.L. (2020)Technology Matters: The human touch in a digital age - a blended approach in mental healthcare delivery with children and young people. Child and adolescent mental health. 202002:120-122. 